\title{
Contribution of Individual Chemoreceptors to Sinorhizobium meliloti Chemotaxis Towards Amino Acids of Host and Nonhost Seed Exudates
}

\author{
Benjamin A. Webb, ${ }^{1}$ Richard F. Helm, ${ }^{2}$ and Birgit E. Scharf ${ }^{1, *}$ \\ ${ }^{1}$ Virginia Tech Department of Biological Sciences and ${ }^{2}$ Virginia Tech Department of Biochemistry, Life Sciences I, Blacksburg, \\ VA 24061, U.S.A.
}

Submitted 22 September 2015. Accepted 18 December 2015.

\begin{abstract}
Plant seeds and roots exude a spectrum of molecules into the soil that attract bacteria to the spermosphere and rhizosphere, respectively. The alfalfa symbiont Sinorhizobium meliloti utilizes eight chemoreceptors (McpT to McpZ and IcpA) to mediate chemotaxis. Using a modified hydrogel capillary chemotaxis assay that allows data quantification and larger throughput screening, we defined the role of $S$. meliloti chemoreceptors in sensing its host, Medicago sativa, and a closely related nonhost, Medicago arabica. S. meliloti wild type and most single-deletion strains displayed comparable chemotaxis responses to host or nonhost seed exudate. However, while the mcpZ mutant responded like wild type to $M$. sativa exudate, its reaction to $M$. arabica exudate was reduced by $80 \%$. Even though the amino acid (AA) amounts released by both plant species were similar, synthetic AA mixtures that matched exudate profiles contributed differentially to the $S$. meliloti wild-type response to $M$. sativa $(23 \%)$ and $M$. arabica $(37 \%)$ exudates, with McpU identified as the most important chemoreceptor for AA. Our results show that $S$. meliloti is equally attracted to host and nonhost legumes; however, AA play a greater role in attraction to $M$. arabica than to $M$. sativa, with McpZ being specifically important in sensing $M$. arabica.
\end{abstract}

The legume-rhizobia symbiosis is characterized by the infection of a legume root by rhizobia resulting in the formation of an organ called the nodule. Inside the nodule, rhizobia transform into bacteroids, which fix atmospheric nitrogen into a utilizable nitrogen source, resulting in greater legume biomass. In return, the legume provides nutrients to the rhizobia. A key step in the initiation of nodulation is the rhizobial recognition of compatible host legume-secreted flavonoids, followed by the legume recognition of compatible microsymbiont-borne Nod factors (Cooper 2007; Hirsch et al. 2001; Jones et al. 2007; van Rhijn and Vanderleyden 1995). The symbiotic partners have developed very specific means of molecular dialogue, resulting in interactions that can be highly exclusive (Garau et al. 2005; Sprent 2007). For example, the soil-dwelling bacterium Sinorhizobium meliloti is hosted by the agriculturally important legume Medicago sativa (alfalfa) (Jones et al. 2007) as well as Melilotus alba (white sweet clover) (Yan et al. 2000) and Medicago truncatula (barrel medic) (Terpolilli et al. 2008). However,

Corresponding author: B. E. Scharf: E-mail: bscharf@vt.edu; Telephone: +1.540.231.0757; Fax: +1.540.231.4043.

(C) 2016 The American Phytopathological Society the closely related Medicago arabica (spotted medic) cannot serve as a host for S. meliloti (Garau et al. 2005).

There are several steps prior to nodulation that contribute to propagation of the symbiosis, including rhizobial chemotaxis, attachment mediated by type IVb pili, exopolysaccharide synthesis and biofilm formation, and flavonoid-Nod factor recognition (Downie 2010; Fujishige et al. 2006; González et al. 1996; Gulash et al. 1984; Kamberger 1979; Rinaudi and González 2009; Sorroche et al. 2010; Wang et al. 2012; Zatakia et al. 2014). Chemotaxis is one of the earliest steps in symbiosis, which enables rhizobia to respond to compounds released by host seed and roots and actively swim toward and accumulate in the spermosphere and rhizosphere (Ames and Bergman 1981; Bergman et al. 1988; Caetano-Anollés et al. 1988b; Dharmatilake and Bauer 1992; Malek 1989; Soby and Bergman 1983; Uren 2000). This initial step has proven to be important for successful symbiotic interactions in several rhizobia-legume partnerships including S. meliloti-alfalfa, Rhizobium trifolii-clover, and Rhizobium leguminosarum-pea (Ames and Bergman 1981; Caetano-Anollés et al. 1988b; Mellor et al. 1987; Miller et al. 2007). Even more, a strain of Bradyrhizobium japonicum with enhanced chemotaxis had a greater nodulation efficiency than the wild type (Althabegoiti et al. 2008).

A germinating seed exudes a multitude of compounds into the soil creating a spermosphere that is unique to that species and even to that seed (Miller and Oldroyd 2012; Nelson 2004). The molecular composition of seed exudate includes amino acids (AA), sugars, lipids, phenolics, proteins, and other metabolites (Barbour et al. 1991; Nelson 2004; Webb et al. 2014). Chemotaxis to their host seed exudates has been shown for S. meliloti, B. japonicum, and R. leguminosarum (Barbour et al. 1991; Gaworzewska and Carlile 1982; Webb et al. 2014), but knowledge of the compounds responsible is mostly lacking. A more comprehensive study of the attractants exuded by alfalfa seeds and the corresponding $S$. meliloti chemoreceptors is required for the development of strains with enhanced chemotaxis toward the host.

Previous work has characterized particular aspects of the $S$. meliloti chemotaxis system regarding the number and domain topology of chemoreceptors (Meier et al. 2007), chemoreceptorligand specificity (Meier et al. 2007; Webb et al. 2014), the twocomponent regulatory components (Amin et al. 2014; Dogra et al. 2012; Riepl et al. 2004; Sourjik and Schmitt 1998), and the unidirectional, speed-variable flagellar motor (Attmannspacher et al. 2005; Eggenhofer et al. 2004; Platzer et al. 1997; Sourjik and Schmitt 1996). S. meliloti has eight genes coding for putative chemoreceptors called methyl-accepting chemotaxis proteins (McpS to McpZ) and one internal chemotaxis protein (IcpA) 
lacking typical methyl-accepting sites (Galibert et al. 2001; Meier et al. 2007). McpS, encoded from a second chemotaxis operon on the pSymA plasmid, is not expressed when cells are motile and a contribution to chemotaxis can be excluded (Meier and Scharf 2009; Meier et al. 2007). The eight chemoreceptors contributing to chemotaxis share a highly conserved, C-terminal signaling domain, which forms a ternary complex with two cytoplasmic chemotaxis proteins, CheA, an autohistidine kinase, and $\mathrm{CheW}$, an adaptor protein. In the absence of an attractant, CheA is autophosphorylated and, subsequently, transfers the phosphoryl group to the response regulator protein CheY2, which interacts with the cytoplasmic face of the flagellar motor and controls the swimming paths of bacteria (Scharf 2002; Sourjik and Schmitt 1996). Seven of the S. meliloti MCP proteins possess two transmembrane regions and a periplasmic region harboring the ligand-binding domain located between the transmembrane helices. In contrast, McpY and IcpA lack such hydrophobic regions and, thus, exhibit a cytosolic localization (Meier et al. 2007). All the chemoreceptors vary in their ligandbinding domains; however, $\mathrm{McpU}, \mathrm{McpV}$, and McpX share specialized domains such as Cache_1 and Cache_2 signaling domains (Meier et al. 2007), which are known to bind small molecules such as AA (Anantharaman and Aravind 2000; Ulrich and Zhulin 2005). McpY possesses a PAS domain, which typically senses redox potential, oxygen, or light (Taylor and Zhulin 1999). Deletion of individual receptor genes causes differential impairments in the chemotactic response toward a variety of small biomolecules tested, including various sugars, five AA, and four organic acids (Meier et al. 2007), but a more complete study is needed to establish their significance in host sensing.

While $S$. meliloti chemotaxis mutants are less competitive in inducing nodule formation with alfalfa (Ames and Bergman 1981; Caetano-Anollés et al. 1988b), little is known about the specific role of individual chemoreceptors in chemotactic host recognition. To date, only $\mathrm{McpU}$ has been characterized in playing a significant role in host plant recognition by mediating chemotaxis to host-derived proline (Webb et al. 2014). To identify $S$. meliloti chemoreceptors important for host sensing, quantitative chemotaxis assays of wild type and single-receptor deletion strains were performed with $M$. sativa seed exudate. In comparison, the seed exudate of the closely related nonhost $M$. arabica was tested to identify differential responses of mutant strains and, concomitantly, differences in exudate attractant composition. Since AA are relatively strong attractants for S. meliloti (Götz et al. 1982; Meier et al. 2007), we also analyzed the AA profiles of host and nonhost exudates, their contribution to chemotaxis, and the involvement of individual chemoreceptors in AA sensing.

\section{RESULTS}

\section{A modified agarose capillary assay}

with automated data acquisition and quantification.

The classic Adler capillary assay allows for the direct quantitative measurement of the response of a population of cells to an attractant or repellent gradient (Adler 1973). However, when several variables are to be tested, such as multiple strains or attractants, or both, this method can become tedious and time consuming. In addition, reproducible removal of the capillary contents can be difficult (Sampedro et al. 2015). The modified agarose or hydrogel capillary assays ease the assessment of chemotaxis, but the results are purely qualitative (Parales and Harwood 2002; Webb et al. 2014). To avoid disadvantages of the classic capillary assay but still generate quantitative data, we combined the simplicity of the modified hydrogel capillary assay with a quantifiable measure of the chemotactic response at the mouths of the capillaries.
The setup of the chemotaxis chambers on a microscope slide is illustrated in Figure 1A. The dimensions of the setup allow for testing of up to ten different variables, such as strains and attractants or repetitions. Once the slide is set on the microscope stage, it is important to utilize a motorized focusing drive with software that allows for memorization of the $x, y$, and $z$ coordinates for each capillary. Figure $1 \mathrm{~B}$ illustrates the pipeline for image acquisition and analysis for one chemotaxis chamber (details discussed below). The combination of the hydrogel capillary assay, motorized focusing drive, and image analysis software enabled quantitative time-course assessments of the chemotactic response, providing detailed comparative information on multiple experimental variables.

\section{Chemotaxis of $S$. meliloti wild type}

toward seed exudate of $M$. sativa and $M$. arabica.

To assess the potencies of germinating seed exudates from $M$. sativa (host) and $M$. arabica (nonhost), the $S$. meliloti wildtype strain RU11/001 was tested with the hydrogel capillary assay for its ability to sense either exudate. In this assay, capillaries contained a hydrogel that was equilibrated with seed exudate. This format allowed efflux of liquid material but prevented cells from swimming into the capillary; thus, cells that were attracted to the exudate accumulated at the mouth of the capillary. A control experiment was performed to rule out a chemotactic response of $S$. meliloti to rhizobial basal medium (RB), used to dissolve the exudate. Comparatively, wild type and the che strain, which lacks all chemoreceptor genes, exhibited no response to RB, whereas wild type displayed a strong response to $M$. sativa exudate, which is abolished for the che strain (Fig. 2A). For quantitative analyses, photographs were taken at the mouth of the capillary every $4 \mathrm{~min}$ under a pseudo dark field, the pixel intensity in front of the capillaries was quantified using the time series analyzer V3 plug-in of the ImageJ software (Balaji 2014), and the intensities were normalized to the greatest intensity observed from the wild type. In this assay, pixel intensity positively correlates with the amount of cells present and, thus, with strength of the chemotactic response. To determine the optimal exudate concentration for optical observation and pixel intensity quantification, a dose-response assay was performed (data not shown). During the first $12 \mathrm{~min}$, the wild type appeared to show a slightly greater response to the $M$. arabica exudate. However, after $12 \mathrm{~min}$, the response to either exudate did not differ from each other (Fig. 2B). The responses plateaued between 20 and 34 min before declining. It should be noted that the plateau in the response is purely physiological, because pixel intensities did not reach a level of saturation in the images. Upon microscopic examination, it was observed that the declination in response after $34 \mathrm{~min}$ was due to the dissemination of cells away from the capillary. This is most likely due to depletion of the attractants from the capillary into the bacterial pond. Taken together, these results support the claim that the chemotactic potencies of $M$. arabica and $M$. sativa seed exudate are relatively equal.

\section{Chemotaxis of single $S$. meliloti chemoreceptor deletion strains to $M$. sativa and $M$. arabica seed exudates.}

To elucidate the importance of each chemoreceptor in $M$. sativa and $M$. arabica exudate sensing, eight single-deletion strains were assessed for their maximum chemotactic response, using the hydrogel capillary assay. The wild type exhibited a maximum response to exudate of $M$. sativa and $M$. arabica between 20 and $34 \mathrm{~min}$ (Fig. 2B); therefore, the pixel intensities of the mutant images pertaining to this time period were averaged and normalized to the greatest average intensity observed for the wild type for the same time period (Fig. 3). McpT, McpU, McpV, 
McpY, and IcpA appeared to contribute similarly to the chemotaxis response toward either legume exudate. A strain lacking mcpU showed the most diminished response toward $M$. sativa and $M$. arabica legume exudates, with reductions to 35 and $20 \%$ of the wild-type response, respectively. Strains lacking $m c p W$ and $m c p X$ displayed significant reductions in response to the exudate of $M$. sativa and $M$. arabica, respectively. Interestingly, the strain lacking $m c p Z$ displayed a pronounced differential response toward the two legume exudates. While this strain responded like wild type to the $M$. sativa exudate, its reaction to the $M$. arabica exudate was reduced by $80 \%$. The results indicate that the attractant compositions of the two legume exudates are different and that $S$. meliloti senses an altered but, presumably, overlapping attractant spectrum in $M$. sativa and $M$. arabica exudates.

\section{Chemotaxis of $S$. meliloti toward $M$. sativa and M. arabica seed exudates and synthetic AA mixtures.}

S. meliloti is able to utilize each proteinogenic AA for growth and displays positive chemotaxis of varied strengths to all of them (Burg et al. 1982; Götz et al. 1982; Jordan 1952; Malek 1989). Therefore, we first analyzed the AA composition of $M$. sativa and $M$. arabica seed exudates to investigate their contribution to host sensing. Exudates from surface-sterilized and germinated seeds of M. sativa and M. arabica were quantified with liquid chromatography mass spectrometry (LC-MS) in conjunction with authentic AA standards. The amounts of each AA exuded by one seed was determined and the concentration of these AA at the seed surface was calculated, using the average $M$. sativa and $M$. arabica seed volumes of 2.17 and $1.84 \mu \mathrm{l}$, respectively. Figure 4 gives a comparison of the concentration of each AA on the seed surface of $M$. sativa or $M$. arabica. Since both legume species are closely related, there appears to be no striking differences between the amounts of each AA exuded. It should be noted that the concentration of each AA is within range of eliciting a chemotactic response, thus making the individual amounts exuded relevant for attraction of $S$. meliloti to the spermosphere and, therefore, for symbiosis with $M$. sativa. Since chemotaxis has been observed for the nonproteinogenic AA, ornithine, citrulline, and cystine (data not shown), their analysis was included in this study.

To assess the chemotactic contribution of the AA fraction in the exudate (proteinogenic AA plus cystine, ornithine, and citrulline), synthetic AA mixtures were created mimicking the exact quantities detected in the seed exudates of $M$. sativa and $M$. arabica, and the wild-type responses to the exudates were compared with the responses to their respective synthetic AA mixture. Here, responses to $M$. sativa exudate and the $M$. sativa synthetic AA mixture were normalized to the highest response observed to the exudate. The same normalization procedure was done for the $M$. arabica exudate and synthetic AA mixture. In both cases, the wild-type response toward the exudate is greater than it is toward the respective synthetic AA mixture (Fig. 5A and B). By adding up the normalized response values

Fig. 1. Hydrogel capillary assay set up and flow chart of image acquisition and analysis. A, Ten chemotaxis chambers are constructed on a microscope slide $(100 \times 50 \times 1 \mathrm{~mm})$. Each chamber consists of an O-ring $8.5 \mathrm{~mm}$ in diameter obtained from the cap of a Sarstedt $1.5-\mathrm{ml}$ screw-cap tube that is sealed to the slide with an application of machine grease. A bacterial suspension $(81 \mu \mathrm{l})$ is placed within the O-ring and a $0.5-\mu \mathrm{l}$ hydrogel capillary is slid into the chamber via a precut section of the O-ring. A glass coverslip is placed on top of the O-ring and is sealed by an application of machine grease. The chemotaxis response is considered to start when the coverslip is set in place. B, Upon microscopic observation of a chemotaxis chamber, the guidelines in the flow chart are followed to acquire images of the chemotaxis response and to quantify the response in each image. for each data set, we determined that the wild-type response to the $M$. sativa and $M$. arabica synthetic AA mixtures is 23 and $37 \%$ of its response to the corresponding exudates, respectively. In conclusion, AA have a greater contribution to nonhost than to host exudate chemotaxis, indicating that host sensing is mediated by additional attractants other than the measured AA.

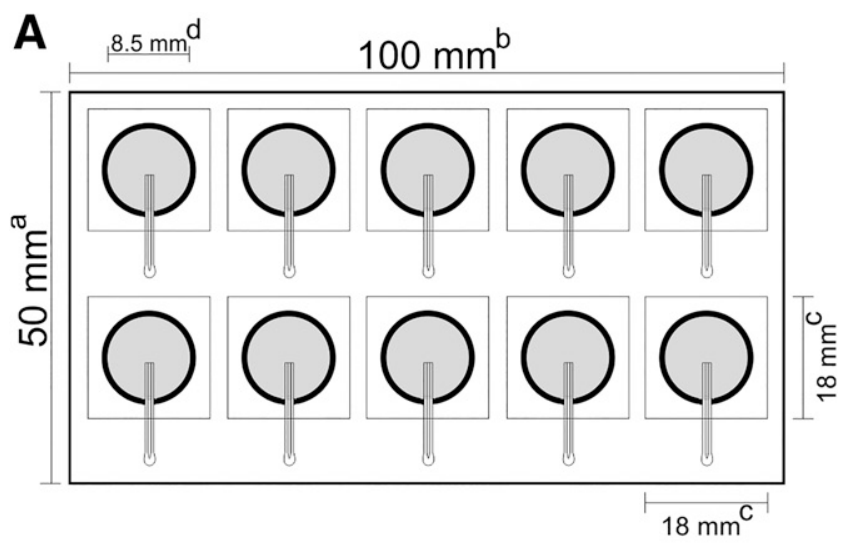

B - Microscope with a motorized
focusing drive

- Set up hydrogel capillaries in chemotaxis chambers

\section{- Observe under 25x pseudo darkfield \\ - Capture 1 image / 2 min}

\section{-Image processing software (Photoshop, Gimp, etc.) - Rotate and align images}

\section{-ImageJ plugin "Time Series Analyzer V3" - Import image stack - Draw regions of interest -Quantify pixel intensity}

- Data processing software (Excel, Origin, etc.)

- Background subtraction

- Normalize to highest response

- Incorporate replicate data

- Plot against time

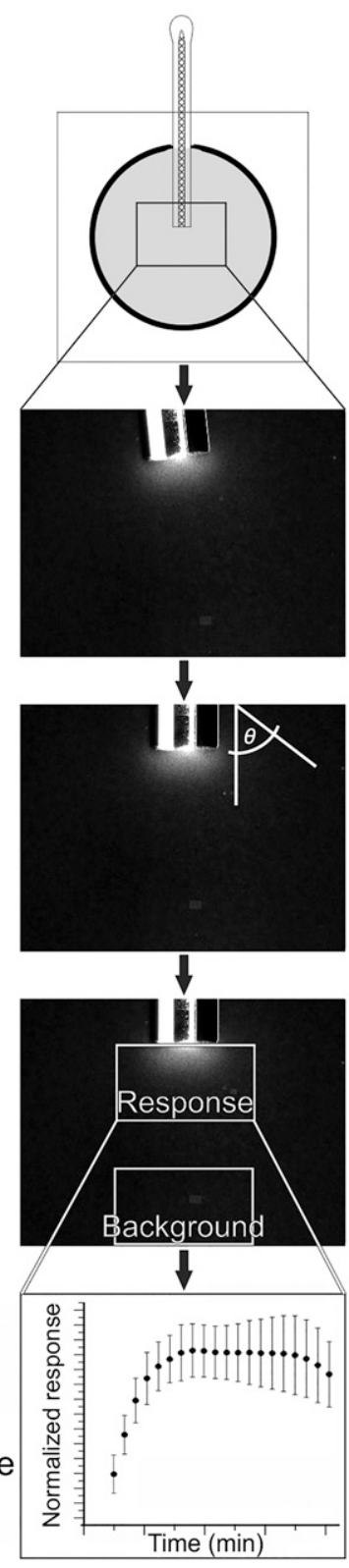


Chemotaxis of single $S$. meliloti chemoreceptor deletion strains to synthetic AA mixture mimicking M. sativa exudate composition.

To determine the chemotactic contribution of individual chemoreceptors toward the synthetic AA mixture of the $S$. meliloti host $M$. sativa, the single-receptor deletion strains were assessed for their maximum chemotactic response, using the hydrogel capillary assay, and responses were quantified (Fig. 6). All deletion strains but $\Delta m c p Y$ exhibited a decreased

A
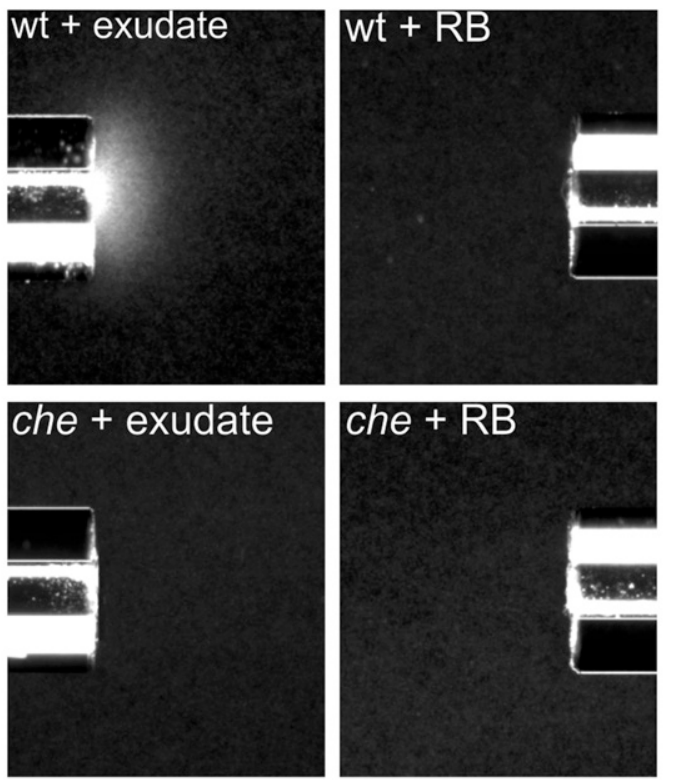

B

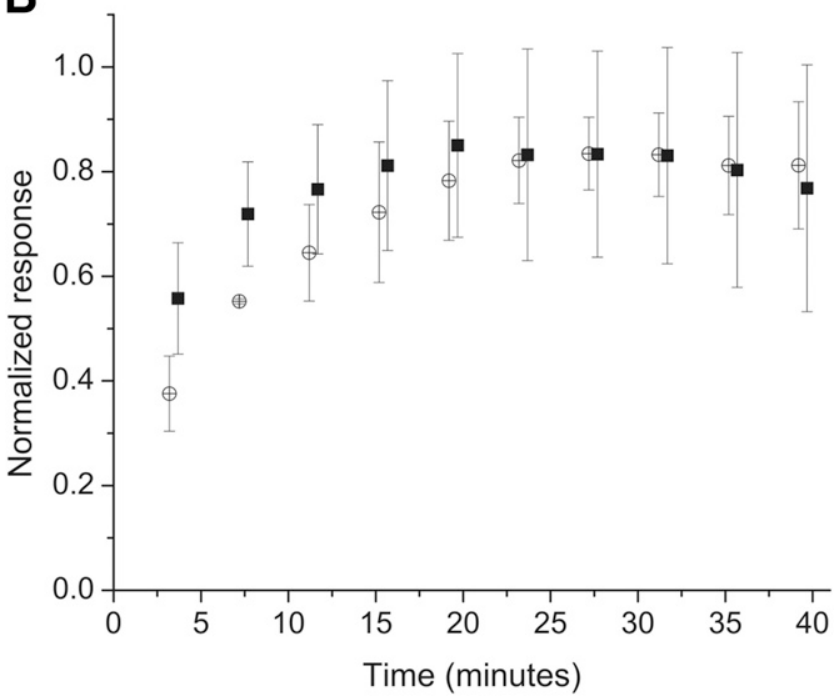

Fig. 2. Sinorhizobium meliloti wild-type response to Medicago sativa and $M$. arabica exudates. A, Responses of $S$. meliloti wild type and the che strain to $M$. sativa seed exudate (exudate) and rhizobial basal medium (RB) were observed at $25 \times$ magnification under pseudo dark field and images were taken at $20 \mathrm{~min}$. Exudate was diluted with RB and was tested at $5 \times$ concentration of the original exudate sample. To allow for ease of visualization, the image brightness, contrast, and intensity were adjusted equally for each image. B, Responses to $M$. sativa $(\bigcirc)$ and $M$. arabica $(\mathbf{\square})$ exudates were observed at $25 \times$ magnification under pseudo dark field, and images were taken with a 1.3-millisecond exposure every $4 \mathrm{~min}$. Normalized response values are the mean and standard deviation of the pixel intensities from three independent experiments. Each response value for a strain is plotted against an average time point. Exudates were tested at $5 \times$ concentration of the original exudate samples. response, although this reduction was not statistically significant for $\Delta m c p T, \Delta m c p V, \Delta m c p W$, and $\Delta m c p Z$. The single deletion strains $\Delta m c p X$ and $\Delta i c p A$ displayed significantly reduced responses of approximately 35 and $40 \%$, respectively, whereas a strain lacking $m c p Y$ exhibited a significantly increased response. Most interestingly, a strain lacking $m c p U$ showed the largest reduction compared with wild type, i.e., a 90\% decrease. This result may indicate that $\mathrm{McpU}$ is not only a receptor for proline, as previously shown (Webb et al. 2014), but proposes a function as a general AA sensor. The intermediate response levels of strains lacking $m c p T, m c p V, m c p W, m c p X$, and $i c p A$ suggests that these chemoreceptors also play a role in AA sensing.

\section{Chemotaxis to synthetic AA mixtures with and without proline.}

To determine if $\mathrm{McpU}$ is important for chemotaxis to AA other than proline, the chemotactic responses of the wild type and the $\Delta m c p U$ strain to the synthetic AA mixture were compared with their responses to a synthetic AA mixture lacking proline. When exposed to the synthetic mixture with proline, as expected, the $\Delta m c p U$ strain exhibited a reduced response compared with the wild type (Fig. 7A and C); however, there appeared to be no difference in the responses to the synthetic mixtures without proline (Fig. 7B and D). This result implies that McpU senses AA other than proline and is likely a general AA sensor.

\section{DISCUSSION}

S. meliloti uses chemotaxis to direct its movements toward host seed and root-exuded attractants (Dharmatilake and Bauer 1992; Malek 1989). This early host-microbe interaction is important for increasing nodulation efficiency, because it allows the bacterial cells to effectively locate infection sites and compete for

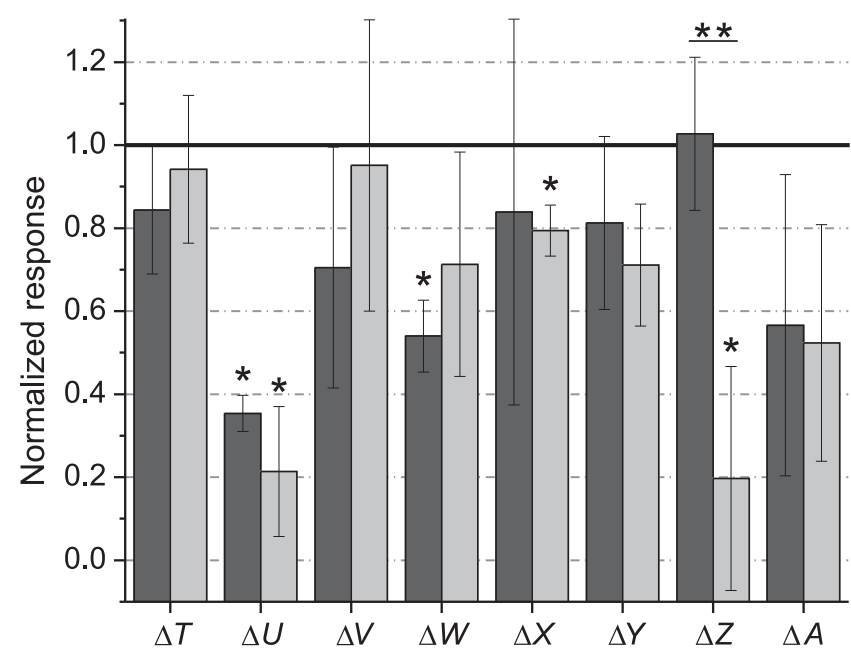

Fig. 3. Responses of Sinorhizobium meliloti wild type and single mcp deletion strains to exudates of Medicago sativa and M. arabica. Responses to $M$. sativa (dark gray bars) and $M$. arabica (light gray bars) exudates were observed at $25 \times$ magnification under pseudo dark field. The wild type exhibited a maximum response to exudates of $M$. sativa and $M$. arabica between 20 and $34 \mathrm{~min}$. Therefore, images taken during this time period were averaged. Responses were normalized to the wild-type response (horizontal line at 1.0) and are the mean and standard deviation from three independent experiments. Exudates were tested at $5 \times$ concentration of the original exudate samples. Data were analyzed for statistical significance, using the one or two sample $t$ test, $P \leq 0.05$. Responses marked with an asterisk $(*)$ are significantly smaller than the wild type, and the responses of $\Delta m c p Z$, marked with $* *$, are significantly different toward both exudates from each other $(P \leq \overline{0.0} 1)$. 
nodulation (Ames and Bergman 1981; Gulash et al. 1984). Germinating alfalfa seeds release compounds that attract $S$. meliloti, which can be viewed as an early recruitment phase of the microsymbiont to the spermosphere. The initial recruitment and establishment of a positional advantage on the roots may be attained by attractants with a longer diffusion range, such as hydrophilic AA, organic acids, sugars, and sugar alcohols (Ma et al. 2005), whereas hydrophobic substances such as phenolic compounds might only have short-range effects. In fact, organic metabolites have been reported to be effective chemoattractants for S. meliloti (Burg et al. 1982; Götz et al. 1982; Meier et al. 2007; Robinson and Bauer 1993), while flavonoids, although proposed as host-specific attractants, elicit a rather small chemotactic response (Caetano-Anollés et al. 1988a; Dharmatilake and Bauer 1992). Since chemical compounds are commonly exuded by many plant species during germination, comparing the attractant profile of $S$. meliloti host and nonhost legumes can lead to a better understanding of the initial stages of symbiont recruitment.

We observed no obvious difference in the strength or time course of attraction of $S$. meliloti wild type to seed exudate of the host $M$. sativa and the closely related nonhost $M$. arabica, in the hydrogel capillary assay (Fig. 2B). This may be simply due to the high phylogenetic proximity of the two medics; however, the specific molecular composition of host and nonhost exudates is unknown. Therefore, we cannot conclude that i) the attractant spectrum is the same for both exudates or ii) $S$. meliloti will accumulate equally well in host and nonhost spermosphere and rhizosphere. To address the first point, a detailed analysis of the secretome and attractome of host versus nonhost exudate is required. The second idea can be challenged by analyzing preferential accumulation of $S$. meliloti in a microfluidic device with competing host and nonhost exudates (Sahari et al. 2014).

When we analyzed the chemotaxis response of single-receptor deletion strains to both exudates, certain parallels and differences emerged. McpU and IcpA appeared to be most important for general exudate sensing, followed by McpV, McpW, McpX, and McpY (Fig. 3). While the role of McpU in proline (Webb et al. 2014) and general AA sensing (Fig. 6) has been uncovered, little is

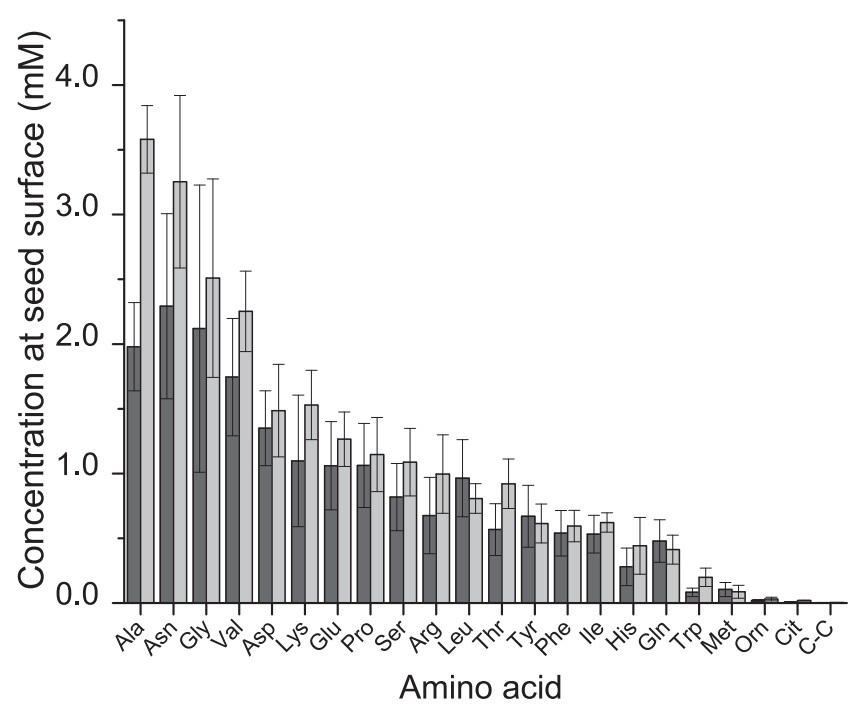

Fig. 4. Amino acids exuded by germinating seeds. Bars indicate the concentrations of amino acids at the surface of a germinating seed as determined by liquid chromatography-mass spectrometry for Medicago sativa (dark gray bar) and $M$. arabica (light gray bar). The seed volumes are 2.17 and $1.84 \mu \mathrm{l}$ for $M$. sativa and $M$. arabica, respectively. Data are organized from highest to lowest concentrations and are the mean and standard deviation from three biological replicates and two to four technical replicates. known about the ligand spectrum of the remaining receptors (Meier et al. 2007). In particular, a function of the cytosolic IcpA in sensing the metabolic state of the cell has been discussed (Meier et al. 2007). Most interestingly, McpZ plays no role in host sensing but is equally as important as McpU for nonhost sensing (Fig. 3). Thus, the attractants sensed by McpZ are absent in the host exudate, which is a clear indication that the attractant profiles of both exudates differ. In conclusion, $S$. meliloti senses a divergent but most likely overlapping attractant spectrum in $M$. sativa and $M$. arabica exudates.

AA are documented as potent attractants (Burg et al. 1982; Götz et al. 1982), and our previous work revealed McpU as proline sensor (Webb et al. 2014). The present study identified McpU as the most important receptor for host sensing (Fig. 3). Therefore, we quantified each proteinogenic AA, citrulline, cystine, and ornithine in the host and nonhost seed exudates, determining their millimolar concentrations per seed to classify their abundances in the spermosphere. Götz et al. (1982) specified the chemotactic thresholds for each proteinogenic AA ranging from $10^{-6} \mathrm{M}$
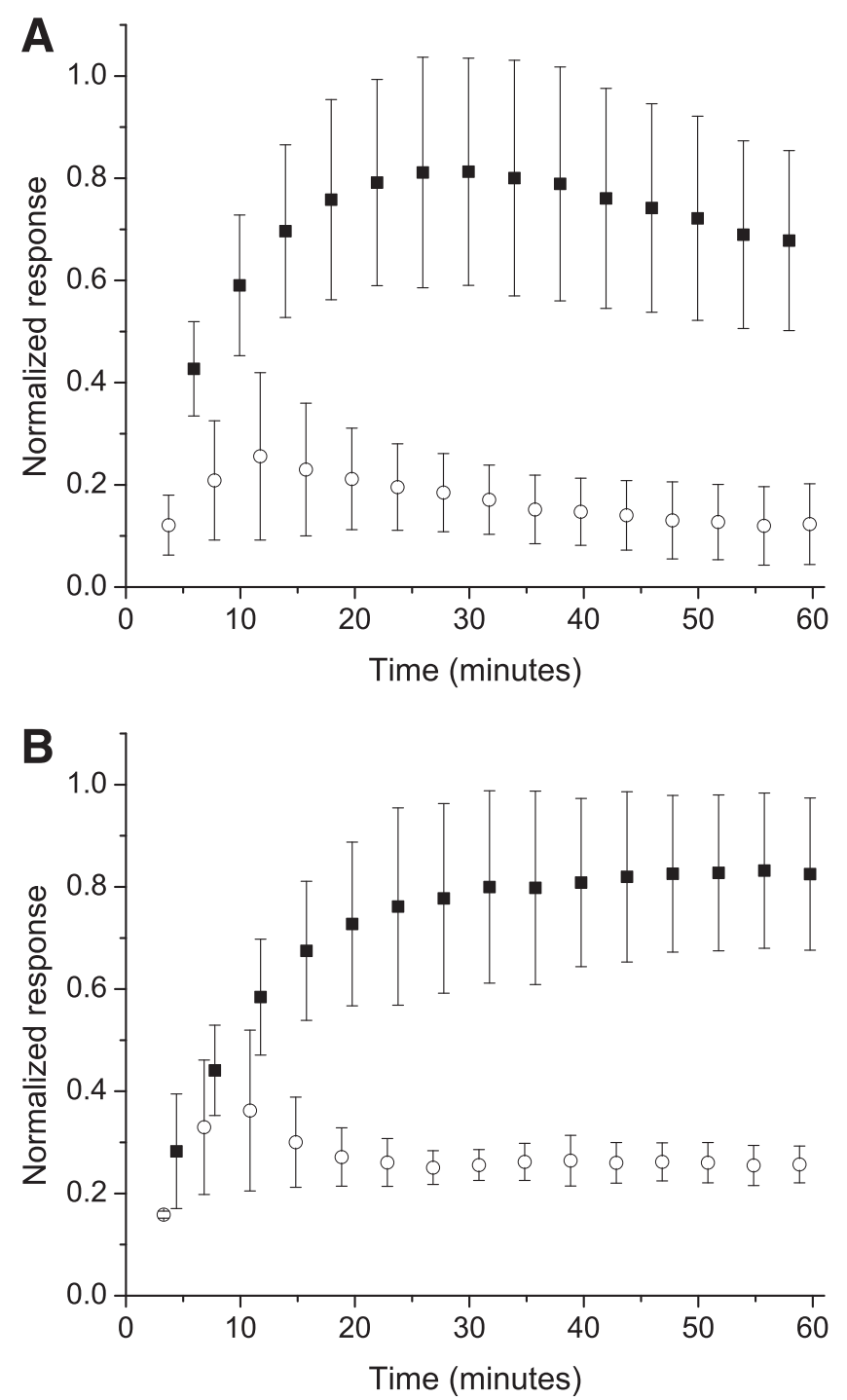

Fig. 5. Wild-type responses to exudates and synthetic amino acid (AA) mixtures. A, Medicago sativa exudate ( $\mathbf{(})$ and synthetic $M$. sativa AA mixture (O). B, $M$. arabica exudate ( $\mathbf{0}$ ) and $M$. arabica synthetic AA mixture $(O)$. To observe responses that are visibly bright enough for quantification, seed exudate and AA mixtures were tested at a $7.6 \times$ concentration of the original exudate samples. Normalized response values are the mean and standard deviation from three independent experiments. Each response value for a strain is plotted against an average time point. 
(proline) to $10^{-4} \mathrm{M}$ (aspartate). Thus, single seeds from both medics exude chemotactically relevant amounts of most proteinogenic AA. The AA profiles appear very similar between the two medics, although with slightly higher amounts exuded by $M$. arabica (Fig. 4). The only significant difference between the two profiles is the concentration of alanine, which is approximately $40 \%$ higher in $M$. arabica exudate. While this difference is small, it could still be influential on the scale of chemotactic strength.

Using the hydrogel capillary assay, we observed the wild-type response to the $M$. sativa and $M$. arabica synthetic AA mixtures to be 23 and $37 \%$ of the respective exudates (Fig. 5), suggesting that non-AA attractants contribute significantly more to the chemotactic response than AA. Potential attractants based upon the metabolomes of Medicago seeds include nonreducing oligosaccharides, phenolics as well as betaines (Horbowicz et al. 1995; Phillips et al. 1995). Due to the presence of these compounds in the exudate, it is conceivable that they modulate chemotaxis to AA. Thus, reported contributions of the AA based upon synthetic mixtures may not directly correlate to AA-based chemotaxis in exudate samples. Studies are currently under way to identify the remaining attractants and characterize differences in the attractant profile between host and nonhost secretomes. The majority of the single deletion strains exhibited a reduced response to the synthetic $M$. sativa AA mixture, inferring that most receptors, directly or indirectly, play a role in AA sensing. Clearly, this study revealed that the proline receptor McpU also senses other AA (Figs. 6 and 7). McpU binds proline in its amino-proximal cache domain (Webb et al. 2014), and it remains to be shown whether the same holds true for other AA.

Identifying environmentally relevant chemotaxis signals in soil bacteria, in particular plant symbionts, and matching them to respective chemoreceptors is a difficult task, due to the complex composition of the rhizosphere. Additionally, bacterial chemoreceptors are known to sense chemically diverse ligands through two different mechanisms, i.e., via direct binding to the periplasmic region or indirectly involving specialized

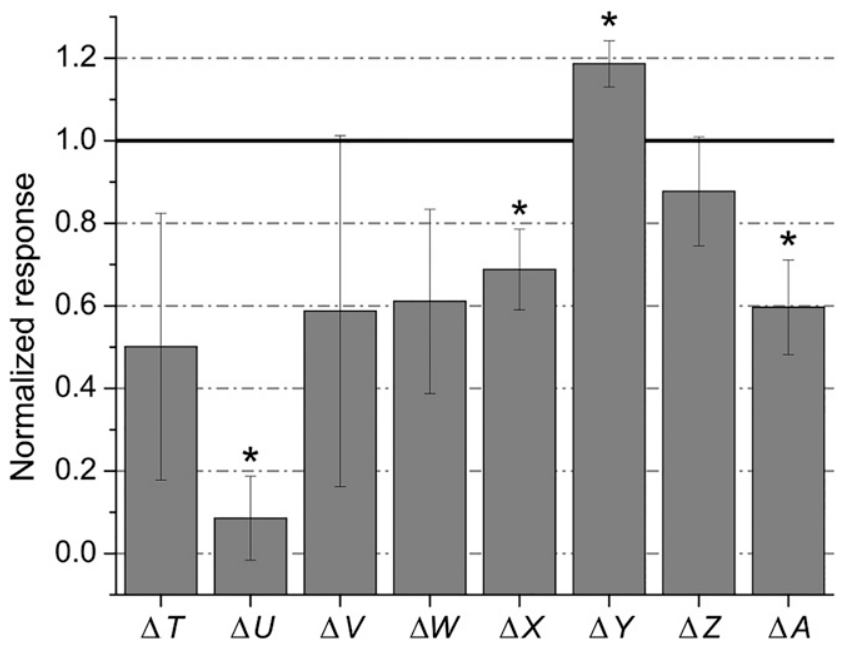

Fig. 6. Responses of single mcp deletion strains to Medicago sativa synthetic amino acid mixture. Responses were observed at $25 \times$ magnification under pseudo dark field. Images taken between 20 and 34 min were averaged and responses are normalized to the wild-type response (horizontal line at 1.0). Data are the mean and standard deviation from three independent experiments. Each response value for a strain is plotted against an average time point. Exudates were tested at $7.6 \times$ concentration of the original exudate samples. Data were analyzed for statistical significance using the one sample $t$ test, $P \leq 0.05$. Responses marked with an asterisk (*) are significantly smaller $(\Delta m c p U, \Delta m c p X, \Delta i c p A)$ or larger $(\Delta m c p Y)$ than the wild type. periplasmic binding proteins. As an example, the Escherichia coli chemoreceptor Tar mediates positive chemotaxis to aspartate through direct binding and senses maltose through binding of maltose-bound maltose-binding protein (Kossmann et al. 1988). McpU appears to be the most important chemoreceptor for host sensing, and it remains to be seen whether it is mediating chemotaxis to attractants other than AA. Furthermore, the attractant profiles of the remaining seven $S$. meliloti chemoreceptors need to be identified to understand their role in host sensing. With this knowledge, a promising avenue for enhancement of $S$. meliloti chemotaxis toward its host would be opened. This goal could be attained by i) increased expression of receptors dedicated to host sensing, ii) genetic tuning of receptors to induce a greater positive chemotactic response toward host-specific exuded attractants, and iii) increased exudation of host-borne attractants. Fine-tuning the chemotaxis process could assist in microsymbiont positioning early during rhizosphere formation, resulting in a greater recruitment of $S$. meliloti to the plant host and, thus, greater crop yields.

\section{MATERIALS AND METHODS}

\section{Bacterial strains and plasmids.}

Derivatives of $S$. meliloti MV II-1 (Kamberger 1979) used are listed in Table 1.

\section{Media and growth conditions.}

S. meliloti strains were grown in TYC $(0.5 \%$ [wt/vol] tryptone, $0.3 \%$ [wt/vol] yeast extract, $0.13 \% \mathrm{CaCl}_{2} \times 6 \mathrm{H}_{2} \mathrm{O}$
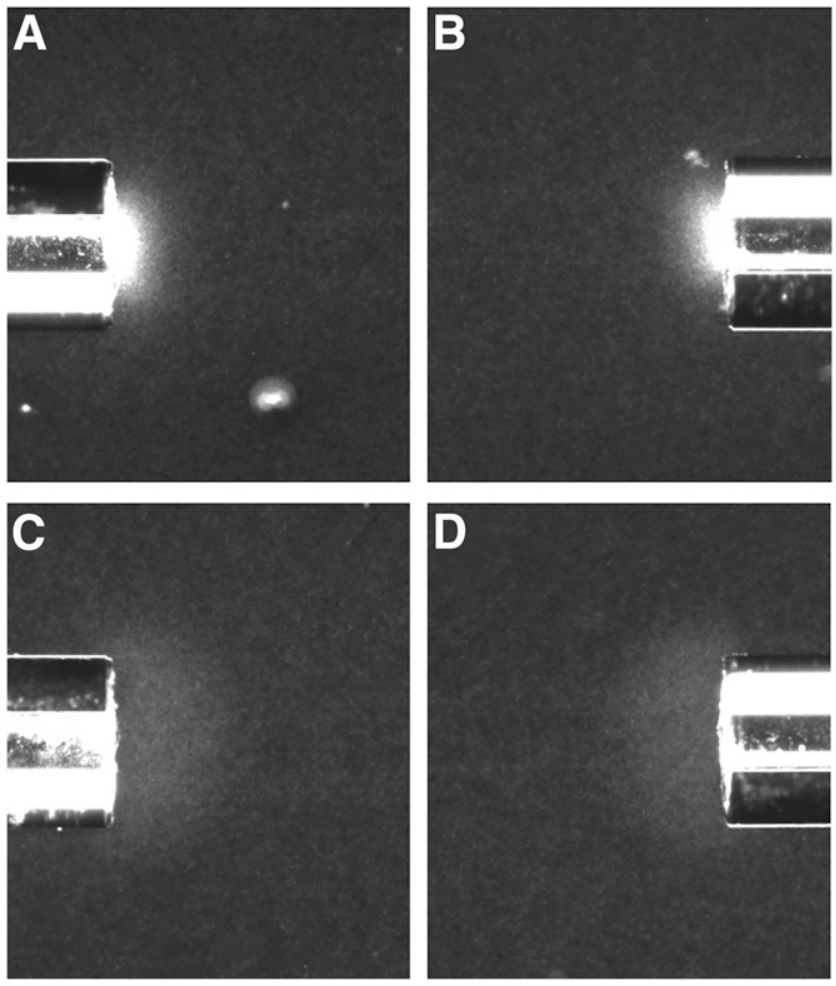

Fig. 7. Responses of wild type and the $\Delta m c p U$ strain to Medicago sativa synthetic amino acid (AA) mixtures with and without proline. A, Wild-type response to AA mixture with proline. B, Wild-type response to AA mixture without proline. $\mathbf{C}, \Delta m c p U$ response to AA mixture with proline. $\mathbf{D}, \Delta m c p U$ response to AA mixture without proline. AA mixtures were tested at a $7.6 \times$ concentration of the original exudate samples. Responses were observed at $25 \times$ magnification under pseudo dark field and images were taken at 10 min. To allow for ease of visualization, the image brightness, contrast, and intensity were adjusted equally for each image. 
[wt/vol] [pH 7.0], streptomycin [600 $\mu \mathrm{g} / \mathrm{ml}])$ at $30^{\circ} \mathrm{C}$ (Bertani 1951; Platzer et al. 1997). Motile cells for hydrogel capillary assays were grown for 2 days in TYC, were diluted 1:1,000 in $3 \mathrm{ml}$ of TYC and were grown overnight. Cultures were then diluted 1:100 in $10 \mathrm{ml}$ of minimal RB $\left(6.1 \mathrm{mM} \mathrm{K}_{2} \mathrm{HPO}_{4}, 3.9 \mathrm{mM}\right.$ $\mathrm{KH}_{2} \mathrm{PO}_{4}, 1 \mathrm{mM} \mathrm{MgSO}$, $1 \mathrm{mM}\left(\mathrm{NH}_{4}\right)_{2} \mathrm{SO}_{4}, 0.1 \mathrm{mM} \mathrm{CaCl}$, $0.1 \mathrm{mM} \mathrm{NaCl}, 0.01 \mathrm{mM} \mathrm{Na}_{2} \mathrm{MoO}_{4}, 0.001 \mathrm{mM} \mathrm{FeSO}, 20 \mu \mathrm{g}$ of biotin per liter, $100 \mu \mathrm{g}$ of thiamine per liter (Götz et al. 1982), layered on Bromfield agar plates with no antibiotics (Sourjik and Schmitt 1996), and were incubated at $30^{\circ} \mathrm{C}$ for approximately $15 \mathrm{~h}$ to an optical density at $600 \mathrm{~nm}\left(\mathrm{OD}_{600}\right)$ of $0.17 \pm 0.02$.

\section{Preparation of seed exudates.}

The Medicago sativa cultivar Guardsman II (registration number CV-203, PI 639220) used in this study was developed from the extensively studied cultivar Iroquois by the Cornell University Agricultural Experiment Station, New York State College of Agriculture and Life Sciences, Cornell University, Ithaca, NY, U.S.A. Seeds were harvested in 2012 and were stored at $4^{\circ} \mathrm{C}$ prior to experiments. Medicago arabica (L.) Huds. (accession SA7746) from a wild population in Siena, Italy in 2008, was cultivated ex situ in Lodi, Italy in 2010, and seeds were harvested and stored at $4^{\circ} \mathrm{C}$ prior to experiments. Seeds $(0.1 \mathrm{~g}$, approximately $47 \pm 1 \mathrm{M}$. sativa seeds and $49 \pm 1 \mathrm{M}$. arabica seeds) were placed in a 50-ml conical tube and were washed four times with $35 \mathrm{ml}$ of autoclaved, sterile-filtered water. Next, seeds were washed once with $8 \mathrm{ml}$ of commercial hydrogen peroxide (3\% in water) for $12 \mathrm{~min}$ and, then, four times with $35 \mathrm{ml}$ of autoclaved, sterile filtered water under slow agitation. Seeds were then transferred to a $125-\mathrm{ml}$ Erlenmeyer flask containing $20 \mathrm{ml}$ of autoclaved, sterile-filtered water. Seeds were jostled to distribute them evenly at the bottom of the flask and were germinated without shaking at $30^{\circ} \mathrm{C}$ for $24 \mathrm{~h}$. To harvest the exudate, the contents were mixed by swirling, a 19-ml aliquot of seed supernatant was removed from the flask, was placed into a $50-\mathrm{ml}$ conical tube, and was flash frozen in liquid nitrogen. The frozen sample was freeze-dried for approximately $48 \mathrm{~h}$ and stored at $-20^{\circ} \mathrm{C}$. Prior to flash freezing, seed exudates were tested for bacterial contamination by microscopic examination and by plating on TYC plates and observation of colony forming units after incubation at $30^{\circ} \mathrm{C}$ for $48 \mathrm{~h}$. Contaminated samples were not included in this study. Seed exudate powders were resuspended to a volume less than the original volume in the flask, thus concentrating the contents to $50 \times$. Aliquots were stored at $-30^{\circ} \mathrm{C}$ and, prior to a chemotaxis assay, they were thawed and then diluted in RB to working concentrations. Postincubation, the germination efficiency was approximately 90 to $95 \%$ for both medics, as determined by radicle emergence. Seed exudate powders were resuspended to a $50 \times$ smaller volume than the original volume in the flask, thus concentrating the contents. Aliquots were stored at $-30^{\circ} \mathrm{C}$, were thawed prior to a chemotaxis assay, and then, were diluted in RB to working concentrations.

\section{Quantification of AA in M. arabica and $M$. sativa seed exudates by LC-MS.}

For each medic, seed exudate residue from six biological replicates was thawed to room temperature, was suspended in $250 \mu \mathrm{l}$ of $\mathrm{RB}$, and was sonicated for $10 \mathrm{~min}$. The samples were centrifuged at $4,000 \times g$ for $10 \mathrm{~min}$ to pellet insoluble material. The six biological replicates were combined in pairs, yielding three biological replicates consisting of $500 \mu \mathrm{l}$ per combined sample. The samples were briefly vortexed and were split into $120-\mu l$ aliquots to be used for either AA quantification or chemotaxis experiments. Aliquots were stored at $-20^{\circ} \mathrm{C}$ prior to use. Aliquots were thawed on ice, were briefly vortexed, were sonicated for $5 \mathrm{~min}$, were centrifuged at $14,000 \times g$ for $5 \mathrm{~min}$ to pellet any remaining insoluble material, and were transferred to microfuge tubes that had been previously rinsed with $100 \%$ ethanol. Exudate samples were diluted 1:1, 1:3, 1:5, and 1:7 in $\mathrm{RB}$, titrated to $\mathrm{pH} 3.5$ with $\mathrm{HCl}$, and $100 \mu \mathrm{l}$ of material per sample was processed using the EZ:faas for free physiological amino acid analysis by LC-MS, as previously described (Webb et al. 2014). AA standard solutions, ranging from 55 to 220 nmoles per milliliter made from the Phenomenex kit (Sigma-Aldrich, St. Louis), were derivatized alongside the exudate samples to establish a calibration curve for each AA. Using Analyst software (AB Sciex, Concord, Canada) for data analysis, the peak area of the internal standard homoarginine was used to normalize the concentration of the AA Ala, Arg, Asn, Asp, Cit, Gln, Glu, Gly, His, Lys, Met, Orn, Pro, Ser, Thr, and Trp, and the peak area of the internal standard homophenylalanine was used to normalize Ile, Leu, Phe, cystine (C-C), and Tyr. The Phenomenex kit does not allow for quantification of cysteine. Results are given as the average concentration derived from three biological replicates, with two to four technical replicates, and duplicate injections per technical replicate.

\section{Creation of synthetic AA mixtures.}

Synthetic mixtures were made with AA from the Fluka Analytical kit 21 L-Amino acids + glycine (lot number 09416), which were dissolved in RB to $50 \times$ the concentrations observed in seed exudates, were aliquoted, and were stored at $-30^{\circ} \mathrm{C}$ until ready for experiments.

\section{Preparation of hydrogel capillaries.}

Capillaries containing a cross-linked hydrogel were prepared essentially according to Webb et al. (2014) with minor modifications. Briefly, capillaries ( $0.5 \mu \mathrm{l}$ of Drummond microcaps) were sealed at one end in a Bunsen burner flame and the inner glass surface was hydroxylated by placing the mouth of the capillaries into a $1 \%(\mathrm{vol} / \mathrm{vol})$ solution of 3-(trichlorosilyl) propyl methacrylate (TPM) (Sigma-Aldrich) diluted in paraffin oil at room temperature for $10 \mathrm{~min}$. After excess TPM was removed via desiccation, the capillaries were submerged in $100 \%$ ethanol and were put under desiccation for approximately $30 \mathrm{~s}$. Ethanol was removed via desiccation and capillaries were wiped with a microfiber cloth to remove any residual material. Capillaries were then quickly passed once through a Bunsen burner flame. A $10 \%$ (wt/vol) solution of poly(ethylene glycol) diacrylate with an average $M_{n}$ number average molecular weight of 6,000 (Sigma-Aldrich) in phosphate buffered saline, $\mathrm{pH} 7.4$, was mixed with $10 \%$ (wt/vol) Irgacure2959 (Sigma-Aldrich) in 70\% ethanol at a ratio of 1:20 to form the precursor solution, which was subsequently pulled into the capillaries by placing them under

Table 1. Sinorhizobium meliloti strains and plasmids

\begin{tabular}{lll}
\hline Strain/plasmid & \multicolumn{1}{c}{$\begin{array}{c}\text { Relevant } \\
\text { characteristics }\end{array}$} & \multicolumn{1}{c}{$\begin{array}{c}\text { Source or } \\
\text { reference }\end{array}$} \\
\hline RU11/001 & $\begin{array}{c}\text { Spontaneous } \mathrm{Sm}^{\mathrm{r}} \\
\text { wild-type strain }\end{array}$ & Pleier and Schmitt 1991 \\
RU11/803 & $\mathrm{Sm}^{\mathrm{r}} ; \Delta m c p W$ & Meier et al. 2007 \\
RU11/804 & $\mathrm{Sm}^{\mathrm{r}} ; \Delta m c p Y$ & Meier et al. 2007 \\
RU11/805 & $\mathrm{Sm}^{\mathrm{r}} ; \Delta m c p X$ & Meier et al. 2007 \\
RU11/815 & $\mathrm{Sm}^{\mathrm{r}} ; \Delta i c p A$ & Meier et al. 2007 \\
RU11/818 & $\mathrm{Sm}^{\mathrm{r}} ; \Delta m c p Z$ & Meier et al. 2007 \\
RU11/828 & $\mathrm{Sm}^{\mathrm{r}} ; \Delta m c p U$ & Meier et al. 2007 \\
RU11/830 & $\mathrm{Sm}^{\mathrm{r}} ; \Delta m c p V$ & Meier et al. 2007 \\
RU11/838 & $\mathrm{Sm}^{\mathrm{r}} ; \Delta m c p T$ & Meier et al. 2007 \\
RU13/149 & $\mathrm{Sm}^{\mathrm{r}} ; \Delta m c p S, \Delta m c p T$, & Meier et al. 2007 \\
& $\Delta m c p U, \Delta m c p V, \Delta m c p W$, & \\
& $\Delta m c p X, \Delta m c p Y, \Delta m c p Z$, & \\
& $\Delta i c p A(c h e)$ &
\end{tabular}

\footnotetext{
a Nomenclature according to Bachmann (1990). $\mathrm{Sm}^{\mathrm{r}}=$ streptomycinresistant. 
vacuum for approximately $30 \mathrm{~s}$. The mouths of the capillaries were submersed in the precursor solution, and photopolymerization was performed for $20 \mathrm{~s}$, using a $365 \mathrm{~nm}, 18 \mathrm{~W} \mathrm{~cm}^{-2}$ UV light source (Omnicure S1000; Vanier, Quebec, Canada). Hydrogel capillaries were observed under $100 \times$ magnification to check for hydrogel integrity. If any hydrogel extended from the mouth of the capillary, the mouth was gently scraped with a wet Kimwipe and was rechecked for hydrogel integrity. Only capillaries with a flush surface at the mouth were used for experiments. Hydrogel capillaries were washed with distilled water and then soaked in distilled water with $1 \mu \mathrm{g}$ of ampicillin per millilter, $1 \mu \mathrm{g}$ of kanamycin per millilter, $1 \mathrm{ug}$ of neomycin per millilter, and $1 \mu \mathrm{g}$ of gentamicin per millilter for at least $4 \mathrm{~h}$ at room temperature, followed by three subsequent washes with the same solution. Hydrogel capillaries could be stored in distilled water with antibiotics at $4^{\circ} \mathrm{C}$ for at least two months.

\section{Hydrogel capillary assay.}

Prior to experiments, hydrogel capillaries were washed and equilibrated twice for $4 \mathrm{~h}$ with RB. AA mixtures and seed exudates suspended in $\mathrm{RB}$ were thawed to room temperature, were briefly vortexed, were centrifuged at $13 \times g$ for $3 \mathrm{~min}$, and were diluted to working concentrations in RB. For experiments including only seed exudates, the solutions were tested at $5 \times$ concentration. For experiments including seed exudates and AA mixtures, the solutions were tested at $7.6 \times$ concentration. For experiments with only the AA mixtures, the solutions were tested at $7.6 \times$ concentration. For equilibration of the capillaries with attractant, capillaries were placed into $50 \mu \mathrm{l}$ of attractant solution per capillary and were left overnight at $4^{\circ} \mathrm{C}$. Cells were harvested by centrifugation at $4,000 \times g$ for $5 \mathrm{~min}$ at room temperature and were suspended with $\mathrm{RB}$ to an $\mathrm{OD}_{600}$ of 0.12 , and $81 \mu \mathrm{l}$ of each strain suspension was added to a circular chemotaxis chamber formed by a microscope slide $(100 \times 50 \mathrm{~mm})$, a cut rubber O-ring with an inner diameter of $8.5 \mathrm{~mm}$ and a thickness of $1 \mathrm{~mm}$ (Sarstedt), and a coverslip. The open end of a hydrogel capillary was inserted into the chemotaxis chamber before the coverslip was placed on top. After the assembly of ten such chambers (Fig. 1A), the microscope slide was placed on the computer-assisted stage of a Zeiss Axio observer research microscope. By programming the Zen software module, the $X, Y$, and $Z$ positions of all ten chambers were observed at $25 \times$ magnification under pseudo dark field and images were taken with a 1.3-millisecond exposure every $2 \mathrm{~min}$.

\section{Quantification of chemotaxis responses.}

Images from the hydrogel capillary assay were imported to the GIMP 2.0 Image Manipulation Program (the GNU Image Manipulation Program Team) and were adjusted by rotation to align the capillaries in such a way that the capillaries rest precisely on top of one another when images were stacked. Rotated images were then imported to ImageJ as an image sequence and the time series analyzer V3 plugin (Balaji 2014) was utilized to obtain the total intensity from a rectangular region of interest (ROI) spanning 551 pixels wide and 294 pixels high. The total intensity of an ROI is reported as 'area,' but will be referred to as 'intensity' in this study. The placement of the ROI was centered in front of the mouth of the capillary to encapsulate the chemotactic response in the images. Images were maintained as .tiff files with no compression. For a single repetition, the mean intensity obtained for the chemotaxis-negative strain (che) at each time point was subtracted from the mean intensities obtained for all other strains. These intensity values were then normalized to the greatest average intensity value observed from the wild-type strain. In all experiments, intensity values were normalized to the highest wildtype response observed. Due to small variations in experimental start time, each area value for a strain is plotted against the average time point. An average time point was derived from the three closest time points for an intensity value from three independent experiments.

\section{ACKNOWLEDGMENTS}

This study was supported by National Science Foundation grant MCB1253234, the Thomas F. and Kate Miller Jeffress Memorial Trust J-1039, and start-up funds from Virginia Tech to B. Scharf. The Virginia Tech Mass Spectrometry Incubator is maintained with funding from the Fralin Life Science Institute of Virginia Tech as well as the National Institute of Food and Agriculture (Hatch grant 228344). We are indebted to B. Behkam for sharing the Zeiss Axio observer research microscope and the Omnicure S1000 UV light source, to L. Pecetti for donation of spotted medic seeds, and T. Arapov, K. Compton, and R. Castaneda Saldana for critical reading of the manuscript.

\section{LITERATURE CITED}

Adler, J. 1973. A method for measuring chemotaxis and use of the method to determine optimum conditions for chemotaxis by Escherichia coli. J. Gen. Microbiol. 74:77-91.

Althabegoiti, M. J., López-García, S. L., Piccinetti, C., Mongiardini, E. J., Pérez-Giménez, J., Quelas, J. I., Perticari, A., and Lodeiro, A. R. 2008. Strain selection for improvement of Bradyrhizobium japonicum competitiveness for nodulation of soybean. FEMS (Fed. Eur. Microbiol Soc.) Microbiol. Lett. 282:115-123.

Ames, P., and Bergman, K. 1981. Competitive advantage provided by bacterial motility in the formation of nodules by Rhizobium meliloti. J. Bacteriol. 148:728-729.

Amin, M., Kothamachu, V. B., Feliu, E., Scharf, B. E., Porter, S. L., and Soyer, O. S. 2014. Phosphate sink containing two-component signaling systems as tunable threshold devices. PLOS Comput. Biol. 10:e1003890.

Anantharaman, V., and Aravind, L. 2000. Cache-A signaling domain common to animal $\mathrm{Ca}^{2+}$-channel subunits and a class of prokaryotic chemotaxis receptors. Trends Biochem. Sci. 25:535-537.

Attmannspacher, U., Scharf, B., and Schmitt, R. 2005. Control of speed modulation (chemokinesis) in the unidirectional rotary motor of Sinorhizobium meliloti. Mol. Microbiol. 56:708-718.

Bachmann, B. J. 1990. Linkage map of Escherichia coli K-12, edition 8 [published erratum appeared in 1991 in Microbiol. Rev. 55:191]. Microbiol. Rev. 54:130-197.

Balaji, J. 2014. Time Series Analyzer Version 3.0. Department of Neurobiology, University of California Los Angeles, U.S.A.

Barbour, W. M., Hattermann, D. R., and Stacey, G. 1991. Chemotaxis of Bradyrhizobium japonicum to soybean exudates. Appl. Environ. Microbiol. 57:2635-2639.

Bergman, K., Gulash-Hoffee, M., Hovestadt, R. E., Larosiliere, R. C., Ronco, P. G., 2nd, and Su, L. 1988. Physiology of behavioral mutants of Rhizobium meliloti: Evidence for a dual chemotaxis pathway. J. Bacteriol. 170:3249-3254.

Bertani, G. 1951. Studies on lysogenesis. I. The mode of phage liberation by lysogenic Escherichia coli. J. Bacteriol. 62:293-300.

Burg, D., Guillaume, J., and Tailliez, R. 1982. Chemotaxis by Rhizobium meliloti. Microbiology 133:162-163.

Caetano-Anollés, G., Crist-Estes, D. K., and Bauer, W. D. 1988a Chemotaxis of Rhizobium meliloti to the plant flavone luteolin requires functional nodulation genes. J. Bacteriol. 170:3164-3169.

Caetano-Anollés, G., Wall, L. G., De Micheli, A. T., Macchi, E. M., Bauer, W. D., and Favelukes, G. 1988b. Role of motility and chemotaxis in efficiency of nodulation by Rhizobium meliloti. Plant Physiol. 86:1228-1235.

Cooper, J. E. 2007. Early interactions between legumes and rhizobia: Disclosing complexity in a molecular dialogue. J. Appl. Microbiol. 103:1355-1365.

Dharmatilake, A. J., and Bauer, W. D. 1992. Chemotaxis of Rhizobium meliloti towards nodulation gene-inducing compounds from alfalfa roots. Appl. Environ. Microbiol. 58:1153-1158.

Dogra, G., Purschke, F. G., Wagner, V., Haslbeck, M., Kriehuber, T., Hughes, J. G., Van Tassell, M. L., Gilbert, C., Niemeyer, M., Ray, W. K., Helm, R. F., and Scharf, B. E. 2012. Sinorhizobium meliloti CheA complexed with CheS exhibits enhanced binding to CheY1, resulting in accelerated CheY1 dephosphorylation. J. Bacteriol. 194:1075-1087.

Downie, J. A. 2010. The roles of extracellular proteins, polysaccharides and signals in the interactions of rhizobia with legume roots. FEMS (Fed. Eur. Microbiol. Soc.) Microbiol. Rev. 34:150-170.

Eggenhofer, E., Haslbeck, M., and Scharf, B. 2004. MotE serves as a new chaperone specific for the periplasmic motility protein, MotC, in Sinorhizobium meliloti. Mol. Microbiol. 52:701-712. 
Fujishige, N. A., Kapadia, N. N., De Hoff, P. L., and Hirsch, A. M. 2006. Investigations of Rhizobium biofilm formation. FEMS (Fed. Eur. Microbiol. Soc.) Microbiol. Ecol. 56:195-206.

Galibert, F., Finan, T. M., Long, S. R., Pühler, A., Abola, P., Ampe, F., Barloy-Hubler, F., Barnett, M. J., Becker, A., Boistard, P., Bothe, G., Boutry, M., Bowser, L., Buhrmester, J., Cadieu, E., Capela, D., Chain, P., Cowie, A., Davis, R. W., Dreano, S., Federspiel, N. A., Fisher, R. F., Gloux, S., Godrie, T., Goffeau, A., Golding, B., Gouzy, J., Gurjal, M., Hernandez-Lucas, I., Hong, A., Huizar, L., Hyman, R. W., Jones, T., Kahn, D., Kahn, M. L., Kalman, S., Keating, D. H., Kiss, E., Komp, C., Lelaure, V., Masuy, D., Palm, C., Peck, M. C., Pohl, T. M., Portetelle, D., Purnelle, B., Ramsperger, U., Surzycki, R., Thebault, P., Vandenbol, M., Vorholter, F. J., Weidner, S., Wells, D. H., Wong, K., Yeh, K. C., and Batut, J. 2001. The composite genome of the legume symbiont Sinorhizobium meliloti. Science 293:668-672.

Garau, G., Reeve, W. G., Brau, L., Deiana, P., Yates, R. J., James, D., Tiwari, R., O'Hara, G. W., and Howieson, J. G. 2005. The symbiotic requirements of different Medicago spp. suggest the evolution of Sinorhizobium meliloti and S. medicae with hosts differentially adapted to soil pH. Plant Soil 276:263-277.

Gaworzewska, E. T., and Carlile, M. J. 1982. Positive chemotaxis of Rhizobium leguminosarum and other bacteria towards root Exudates from legumes and other plants. J. Gen. Microbiol. 128:1179-1188.

González, J. E., York, G. M., and Walker, G. C. 1996. Rhizobium meliloti exopolysaccharides: Synthesis and symbiotic function. Gene 179:141146.

Götz, R., Limmer, N., Ober, K., and Schmitt, R. 1982. Motility and chemotaxis in two strains of Rhizobium with complex flagella. J. Gen. Microbiol. 128:789-798.

Gulash, M., Ames, P., Larosiliere, R. C., and Bergman, K. 1984. Rhizobia are attracted to localized sites on legume roots. Appl. Environ. Microbiol. 48:149-152.

Hirsch, A. M., Lum, M. R., and Downie, J. A. 2001. What makes the rhizobia-legume symbiosis so special? Plant Physiol. 127:1484-1492.

Horbowicz, M., Obendorf, R. L., McKersiec, B. D., and Viands, D. R. 1995. Soluble saccharides and cyclitols in alfalfa (Medicago sativa L.) somatic embryos, leaflets, and mature seeds. Plant Sci. 109:191-198.

Jones, K. M., Kobayashi, H., Davies, B. W., Taga, M. E., and Walker, G. C. 2007. How rhizobial symbionts invade plants: The SinorhizobiumMedicago model. Nat. Rev. Microbiol. 5:619-633.

Jordan, D. C. 1952. Studies on the legume root nodule bacteria. 3. Growth factor requirements for effective, ineffective, and parasitic strains. Can. J. Bot. 30:693-700

Kamberger, W. 1979. An Ouchterlony double diffusion study on the interaction between legume lectins and rhizobial cell surface antigens. Arch. Microbiol. 121:83-90.

Kossmann, M., Wolff, C., and Manson, M. D. 1988. Maltose chemoreceptor of Escherichia coli: Interaction of maltose-binding protein and the tar signal transducer. J. Bacteriol. 170:4516-4521.

Ma, Y., Zhu, C., Ma, P., and Yu, K. T. 2005. Studies on the diffusion coefficients of amino acids in aqueous solutions. J. Chem. Eng. Data 50: 1192-1196.

Malek, W. 1989. Chemotaxis in Rhizobium meliloti strain L5.30. Microbiology 152:611-612.

Meier, V. M., Muschler, P., and Scharf, B. E. 2007. Functional analysis of nine putative chemoreceptor proteins in Sinorhizobium meliloti. J. Bacteriol. 189:1816-1826.

Meier, V. M., and Scharf, B. E. 2009. Cellular localization of predicted transmembrane and soluble chemoreceptors in Sinorhizobium meliloti. J. Bacteriol. 191:5724-5733.

Mellor, H. Y., Glenn, A. R., Arwas, R., and Dilworth, M. J. 1987. Symbiotic and competitive properties of motility mutants of Rhizobium trifolii Ta1. Arch. Microbiol. 148:34-39.

Miller, J. B., and Oldroyd, G. E. D. 2012. The role of diffusible signals in the establishment of rhizobial and mycorrhizal symbioses. Pages 1-30 in: Signaling and Communication in Plants. S. Perotto and F. Baluŝka, eds. Springer-Verlag Berlin.

Miller, L. D., Yost, C. K., Hynes, M. F., and Alexandre, G. 2007. The major chemotaxis gene cluster of Rhizobium leguminosarum bv. viciae is essential for competitive nodulation. Mol. Microbiol. 63:348-362.

Nelson, E. B. 2004. Microbial dynamics and interactions in the spermosphere. Annu. Rev. Phytopathol. 42:271-309.

Parales, R. E., and Harwood, C. S. 2002. Bacterial chemotaxis to pollutants and plant-derived aromatic molecules. Curr. Opin. Microbiol. 5:266-273.
Phillips, D. A., Wery, J., Joseph, C. M., Jones, A. D., and Teuber, L. R. 1995. Release of flavonoids and betaines from seeds of seven Medicago species. Crop Sci. 35:805-808.

Platzer, J., Sterr, W., Hausmann, M., and Schmitt, R. 1997. Three genes of a motility operon and their role in flagellar rotary speed variation in Rhizobium meliloti. J. Bacteriol. 179:6391-6399.

Pleier, E., and Schmitt, R. 1991. Expression of two Rhizobium meliloti flagellin genes and their contribution to the complex filament structure. J. Bacteriol. 173:2077-2085.

Riepl, H., Scharf, B., Schmitt, R., Kalbitzer, H. R., and Maurer, T. 2004. Solution structures of the inactive and $\mathrm{BeF}_{3}$-activated response regulator CheY2. J. Mol. Biol. 338:287-297.

Rinaudi, L. V., and González, J. E. 2009. The low-molecular-weight fraction of exopolysaccharide II from Sinorhizobium meliloti is a crucial determinant of biofilm formation. J. Bacteriol. 191:7216-7224.

Robinson, J. B., and Bauer, W. D. 1993. Relationships between $\mathrm{C}_{4}$ dicarboxylic acid transport and chemotaxis in Rhizobium meliloti. J. Bacteriol. 175:2284-2291.

Sahari, A., Traore, M. A., Scharf, B. E., and Behkam, B. 2014. Directed transport of bacteria-based drug delivery vehicles: Bacterial chemotaxis dominates particle shape. Biomed. Microdevices 16:717-725.

Sampedro, I., Parales, R. E., Krell, T., and Hill, J. E. 2015. Pseudomonas chemotaxis. FEMS (Fed. Eur. Microbiol. Soc.) Microbiol. Rev.39:17-46.

Scharf, B. 2002. Real-time imaging of fluorescent flagellar filaments of Rhizobium lupini $\mathrm{H} 13-3$ : Flagellar rotation and $\mathrm{pH}$-induced polymorphic transitions. J. Bacteriol. 184:5979-5986.

Soby, S., and Bergman, K. 1983. Motility and chemotaxis of Rhizobium meliloti in soil. Appl. Environ. Microbiol. 46:995-998.

Sorroche, F. G., Rinaudi, L. V., Zorreguieta, A., and Giordano, W. 2010. EPS II-dependent autoaggregation of Sinorhizobium meliloti planktonic cells. Curr. Microbiol. 61:465-470.

Sourjik, V., and Schmitt, R. 1996. Different roles of CheY1 and CheY2 in the chemotaxis of Rhizobium meliloti. Mol. Microbiol. 22:427-436.

Sourjik, V., and Schmitt, R. 1998. Phosphotransfer between CheA, CheY1, and CheY2 in the chemotaxis signal transduction chain of Rhizobium meliloti. Biochemistry 37:2327-2335.

Sprent, J. I. 2007. Evolving ideas of legume evolution and diversity: A taxonomic perspective on the occurrence of nodulation. New Phytol. 174:11-25.

Taylor, B. L., and Zhulin, I. B. 1999. PAS domains: Internal sensors of oxygen, redox potential, and light. Microbiol. Mol. Biol. Rev. 63:479-506.

Terpolilli, J. J., O’Hara, G. W., Tiwari, R. P., Dilworth, M. J., and Howieson, J. G. 2008. The model legume Medicago truncatula A17 is poorly matched for $\mathrm{N}_{2}$ fixation with the sequenced microsymbiont Sinorhizobium meliloti 1021. New Phytol. 179:62-66.

Ulrich, L. E., and Zhulin, I. B. 2005. Four-helix bundle: A ubiquitous sensory module in prokaryotic signal transduction. Bioinformatics 21 (Suppl 3):iii45-iii48.

Uren, N. C. 2000. Types, amounts and possible functions of compounds released into the rhizosphere by soil-grown plants. Pages 19-40 in: The Rhizosphere: Biochemistry and Organic Substances at the Soil-Plant Interface. R. Pinton, Z. Varanini, and P. Nannipiero, eds. CRC Press, New York.

van Rhijn, P., and Vanderleyden, J. 1995. The Rhizobium-plant symbiosis. Microbiol. Rev. 59:124-142.

Wang, D., Yang, S., Tang, F., and Zhu, H. 2012. Symbiosis specificity in the legume: Rhizobial mutualism. Cell. Microbiol. 14:334-342.

Webb, B. A., Hildreth, S., Helm, R. F., and Scharf, B. E. 2014. Sinorhizobium meliloti chemoreceptor McpU mediates chemotaxis toward host plant exudates through direct proline sensing. Appl. Environ. Microbiol. 80: 3404-3415.

Yan, A. M., Wang, E. T., Kan, F. L., Tan, Z. Y., Sui, X. H., Reinhold-Hurek, B., and Chen, W. X. 2000. Sinorhizobium meliloti associated with Medicago sativa and Melilotus spp. in arid saline soils in Xinjiang, China. Int. J. Syst. Evol. Microbiol. 50:1887-1891.

Zatakia, H. M., Nelson, C. E., Syed, U. J., and Scharf, B. E. 2014. ExpR coordinates the expression of symbiotically important, bundle-forming Flp pili with quorum sensing in Sinorhizobium meliloti. Appl. Environ. Microbiol. 80:2429-2439.

\section{AUTHOR-RECOMMENDED INTERNET RESOURCE}

U. S. National Institutes of Health ImageJ software: http://imagej.nih.gov/ij 